\title{
An open letter
}

To any impressionable young school leavers who are considering joining the space corps.

\section{Martin Hayes}

If you are considering joining the space corps, I’ve got one word for you: don't.

Don't do it.

No, seriously now, don't even think about it.

Wait. What's that you say? Why the hell not? Yeah, I knew you'd say that. Okay wise guy, here goes nothing.

You know those adverts that you see during your favourite TV shows? They're all lies. That foxy waitress who is so impressed by the young hotshot who just graduated from the academy that her clothes just seem to fall off of their own volition - they think we're all morons. That handsome, well-built guy with the oiled biceps dodging the ship through the asteroid belt - never happened, would never happen, will never happen.

It's not glamorous, it's not exciting, it pays less than what I used to make as a welder and it will really screw up your social life. Still don't believe me? Huh, I figured as much.

Okay, so you probably think that life in the space corps is all thrills, spills and madcap adventures, gritting your teeth while you make split-second, life or death decisions. Yeah?

Wrong.

The truth is that it's supremely, monstrously, interminably boring. Even if you're picked for the induction course and you manage to trudge your way through all the mental training and assault courses, the personality tests and press-ups, it can still take years before you even set foot on a ship to begin your first mission. And believe me, that's when the fun really goes out of it.

Do you want to know the worst thing about waking up from a 19-month cryosleep?

The size of the bloody erection, that's what.

Seriously, you could hammer tent pegs into Europan sheet-ice with the thing. It's agony. On my last trip out it took five days for the bruising to fade away. And I had to sit down to take a leak. You try going to the ship's doctor and telling her that you've got acute thrombosis of the penis. There's a conversation you won't forget in a hurry.

And then there are all the other hassles of cryo-sleep. You haven't washed your face for a year and a half so you're riddled with zits, and if you've slept a bit funny on your arm you'll be walking like Quasimodo for the next three weeks - and the breath!

Plus, it's practically a given that at least one of your colleagues will be playing tonsil hockey with some kind of hideous facesucking parasite. You'll try to take it off but it never works. It'll have acid for blood or something, as usual. We used to run a book on who would be the one sporting the alien balaclava but it's not worth
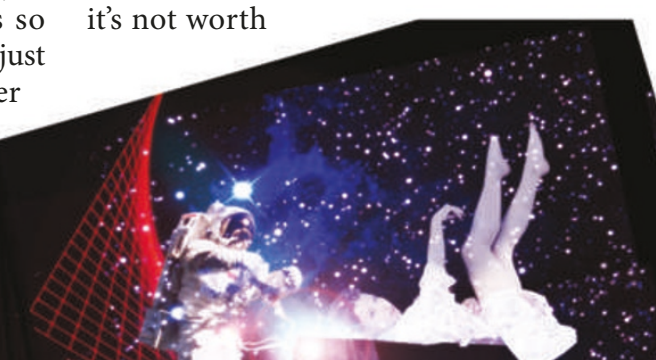

door. There isn't a bulkhead in the world thick enough to shield your ears from those high-pitched supernatural delights.

And everyone knows that the companies who run the ships are a bunch of mean sods. They never put proper lighting in the hallways, they're always dark and shadowy and a little bit on the scary side, and for some unknown reason there's always a leaking pipe somewhere, usually down in the cargo bay, constantly drip-drip-dripping water and driving everyone crazy.

Here's what I'd like to know, if they can build a spaceship the size of a small city and fly it through interstellar space at almost the speed of light, why can't they fix a leaking pipe? Eh? Well?

You should also forget all those exciting rumours you've heard about the aliens. Apart from the face-sucking-leech-beasts (who, despite their tendency to pounce on you when you least expect it, can at least be taught some basic domestic skills), we've found only one other species of intelligent life and they turned out to be the extrasolar equivalent of Morris Dancers — boring bastards to a man, and no, that's not sexist, they don't have females, they spontaneously reproduce in a little transparent bag that they carry around between their knees, and yes, that is as pretty as it sounds.

So, take my advice, stay on Earth. Get a job in a supermarket or something. It's less hassle, the money is better and at least I won't have to look at your sallow, boggle-eyed face over breakfast.

it any more, you can't get good odds. Last time out I was 3 to 1 on.

But the parasites aren't even the half of it.

If I told you about all the times my fellow crew members have been haunted by ethereal-yet-physical representations of their recently deceased wives, I'd be here all day. It's almost become a cliché at this point. For some guys, that's the only reason they go on missions anymore, to catch up with their dead wives, have a bit of a chat, let them know how the kids are getting on, all that.

And the nocturnal noises - just let me tell you this: it's no fun trying to get back to sleep when you've been woken at a quarter to four in the morning by the syrupy moans of your shipmate getting frisky with the ghost of his dead wife in the cabin next
Yours sincerely,

Frank Ellison

Hydrogeological Survey Assistant

18th July, 2217

DS Research Ship Ptolemy - docked at Ganymede space port.

PS. I forgot to mention: never, on any account, and I mean never, trust the AI computer. It wants to kill you.

PPS. Seriously. Don't.

Martin Hayes lives in Arklow, a small town on the east coast of Ireland. He spends his days drinking strong tea and staring maniacally at a Crookes Radiometer. You can visit him at www.paroneiria.com.

Join the discussion of Futures in Nature at go.nature.com/QMAm2a 